\title{
Relationship between religiosity, religious coping and socio-demographic variables among out-patients with depression or diabetes mellitus in Enugu, Nigeria.
}

\author{
Kennedy U Amadi ${ }^{1}$, Richard Uwakwe ${ }^{2}$, Appolos C Ndukuba ${ }^{1}$, Paul C Odinka ${ }^{1}$, Monday N Igwe ${ }^{3}$, \\ Nicodemus K Obayi ${ }^{3}$, Mark S Ezeme ${ }^{4}$
}

1. Department of Psychological Medicine, College of Medicine, University of Nigeria, Enugu Campus, Enugu State, Nigeria.

2. Faculty of Medicine, Nnamdi Azikiwe University, Nnewi Campus, Anambra State, Nigeria.

3. Department of Psychiatry, Federal Teaching Hospital, Abakaliki, Ebonyi State, Nigeria.

4. Department of Psychiatry, Enugu State University Teaching Hospital (Parklane), Enugu State Nigeria.

\begin{abstract}
Background: Religion is a powerful coping strategy. Diabetes and depression are common conditions in our environment that induce psychological distress, thus requiring coping for better outcome. Studies indicate that increased religiosity is associated with better outcome in clinical and general populations. Therefore, studies of the distribution of religiosity and religious coping among these populations are essential to improve outcome.

Objectives: To assess the association between religiosity, religious coping in depression and diabetes mellitus, and selected sociodemographic variables (age, gender and occupational status).

Methods: Using simple random sampling we recruited 112 participants with diabetes and an equal number with depression consecutively, matching for gender. Religiosity was determined using religious orientation scale (revised), religious coping with brief religious coping scale and socio-demographic variables with a socio-demographic questionnaire.

Results: Intrinsic religiosity was greater among older people with depression than among older people with diabetes $(\mathrm{t}=5.02, \mathrm{p}<0.001)$; no significant difference among young people with depression and diabetes $(\mathrm{t}=1.47$, $\mathrm{p}=0.15)$. Positive religious coping was greater among older people with depression than among older people with diabetes $(\mathrm{t}=2.31, \mathrm{p}=0.02)$; no difference among young people with depression and diabetes $(\mathrm{t}=0.80, \mathrm{p}=0.43)$. Females with depression had higher intrinsic religiosity scores than males with depression $(\mathrm{t}=3.85, \mathrm{p}<0.001)$; no difference in intrinsic religiosity between females and males with diabetes $(\mathrm{t}=0.99, \mathrm{p}=0.32)$. Positive religious coping was greater among participants with diabetes in the low occupational status $(\mathrm{t}=2.96, \mathrm{p}<0.001)$ than those in the high occupational status.
\end{abstract}

Conclusion: Religion is indeed a reliable coping method, most commonly used by the elderly and females with depression. Positive religious coping is more common among diabetic patients who are in the low occupational status.

Keywords: Religiosity, religious coping, depression, diabetes mellitus, socio-demographic variables..

DOI: http://dx.doi.org/10.4314/ahs.v16i2.18

Cite as: Amadi KU, Uwakwe R, Ndukuba AC, Odinka PC, Igwe MN, Obayi NK, et al. Relationship between religiosity, religious coping and socio-demographic variables among out-patients with depression or diabetes mellitus in Enugu, Nigeria. Afri Health Sci 2016;16(2): 497-506. http://dx.doi.org/10.4314/abs.v16i2.18

\section{Introduction}

Depression and diabetes mellitus are common and both are major contributors to the global burden of disease and disability measured in Disability Adjusted Life Years

\section{Corresponding author:}

Kennedy U Amadi,

Department of Psychological Medicine,

College of Medicine, University of Nigeria,

Enugu Campus, Enugu State, Nigeria.

E-mail: kennedy.amadi@unn.edu.ng

Phone: +2348033495689
(DALYs). ${ }^{1,2}$ The WHO estimates that globally 350 million people of all ages suffer from depression ${ }^{1}$ while the global prevalence of diabetes mellitus in 2014 was estimated to be $9 \%$ among adults aged 18 years and above. ${ }^{2}$ Apart from the prevalence of both conditions being separately high, depression is known to have a high rate of co-morbidity with diabetes, ${ }^{3}$ and many other chronic medical/ surgical conditions (including cancers) that induce both subclinical and diagnosable psychological distress. ${ }^{4-6}$

In Nigeria, there has been a progressive increase in the prevalence of diabetes mellitus with increased burden of

African Health Sciences Vol 16 Issue 2, June 2016 
the disease. Nearly two decades ago (1997), prevalence of diabetes mellitus in Nigeria was estimated to be $2.2 \%$, and this continues to increase such that the International Diabetes Federation recorded 5.0\% in its 2013 Diabetes Atlas as national prevalence of DM in Nigeria adjusted to national population. ${ }^{8,9}$ With increased urbanization many Nigerians are adopting western lifestyle with decreased physical activity, sedentary lifestyle and excessive intake of calories. This contributes to obesity, a risk factor for diabetes mellitus. The increased prevalence of diabetes mellitus is associated with considerable morbidity and mortality with significant economic cost. Studies ${ }^{10,11}$ have shown a bidirectional relationship between DM and MDD with increased psychological distress and physical complications where they co-exist. Both conditions separately and as co-morbidities are common in our environment.

The psychological distress associated with chronic medical disorders requires that some form of adjustment in lifestyle and behavior is necessary for achieving good psychosocial outcome. Studies have indicated a positive association between religious involvement and better adaptation to chronic medical illness such as diabetes because religious coping has been associated with improved attendance at scheduled medical appointments, and better compliance with medication. ${ }^{12}$ In a study among Turkish adults with type 1 or type 2 diabetes mellitus, religion was found to be one of the most frequently used coping strategies. $^{6}$ Intrinsic religiosity (being wholly committed and motivated by one's religious beliefs) has been found to be negatively associated with depressive symptoms ${ }^{13}$, and to be strongly associated with increased speed with which individuals' depressive symptoms could subside, even after controlling for a variety of potential confounds. ${ }^{14}$ Moreover, devout religious commitment has been associated with decreased risk for depression and suicide. ${ }^{15,16}$ Individuals who are religious (with high intrinsic and extrinsic religiosities) are more likely to be involved in religious coping. ${ }^{17,18}$

Religious beliefs and practices are widespread around the world as shown by systematic research, and it is known to be a source of strength, resilience and enables people to make sense of suffering. ${ }^{18}$ It has been reported that there is a positive relationship between religiosity with better overall health (physical and mental) and better quality of life. ${ }^{19}$ This effect has been attributed to the fact that religion may help to moderate or even mediate the potentially damaging physiological responses to stress through its unique coping efforts; fostering greater social support, hope and optimism; enhancing positive emotions and preventing depression and suicide. ${ }^{20}$ Many researchers have advocated for the inclusion of religious/spiritual dimensions in our everyday medical and psychiatric assessments and practice. ${ }^{21,22}$

Socio-demographic variables appear to influence the use of religion as a coping resource. For instance, in the United States, studies have indicated the preponderance of religiosity among ethnic minorities, women, older people and married persons. ${ }^{23,24}$ Religious coping thought to be "a theoretically appealing measure of functional religiousness" was found to be more significantly associated with being Black or Hispanic. ${ }^{25}$ Phelps et $\mathrm{al}^{25}$ showed that patients who scored high on positive religious coping were younger, less educated, less likely to be married and more likely to be recruited from the Texas sites in the United States inhabited more by African Americans. In a Brazilian national survey of religious involvement and sociodemographic factors, it was found that older age and female gender were independently associated with higher levels of subjective and organizational religiousness after controlling for other sociodemographic factors. ${ }^{26}$ Several other studies have reported varying levels of religiosity and religious coping among different socio-demographic categories including people of various socioeconomic status. $^{27-32}$.

In order to improve health care services and research, it is necessary to know how religiosity and religious coping are distributed among the clinical and general populations especially as this resource is widely available to Africans and people of low socio-economic status who may have more difficulties in accessing available health care. Interestingly, there is a paucity of literature on the use of religiosity in coping with mental and physical disorders in our environment, particularly among clinical populations in hospitals. This study is designed to fill in this gap, and it is aimed at establishing the relationship between religiosity, religious coping and socio-demographic variables among a clinical population of hospital attendees with depression or diabetes mellitus in two tertiary hospitals in Enugu, South-East Nigeria. It is hoped that the findings of this study would contribute to effective treatment for these common conditions in our environment. 


\section{Methods \\ Study design}

This was a cross-sectional comparative study of outpatient clinic attendees with Diabetes Mellitus (DM) or Major Depressive Disorder (MDD). Participants with DM (index) were recruited from the University of Nigeria Teaching Hospital (UNTH), Enugu while participants with MDD (comparator) were recruited from the Federal Neuropsychiatric Hospital (FNH), Enugu as well as the psychiatric out-patient clinics of UNTH, Enugu.

\section{Sample size determination}

The sample size was calculated using the formula below ${ }^{33}$ : $\mathrm{N}=\mathrm{z} 2 \mathrm{pq} / \mathrm{d} 2$, where $\mathrm{N}=$ sample size

$\mathrm{Z}=$ confidence interval, a constant, which is 1.96 .

$\mathrm{p}=$ prevalence (the crude prevalence of diabetes mellitus in Nigeria is $7 \%)^{34}$

$\mathrm{q}=100-\mathrm{p}$.

$\mathrm{d}=$ level of confidence which is $5 \%$ (or 0.05 ).

The sample size on substitution was:

$\mathrm{N}=\mathrm{z} 2 \mathrm{pq} / \mathrm{d} 2=1.96 \times 1.96 \times 0.07 \times 0.93 / 0.05 \times 0.05$ $=100.03526$, approximately 101 .

To make allowance for attrition, a 10\% increase was made by adding 11 i.e. $10 \%$ of 101 , approximately 11 . This gave a minimum sample size of 112 , each for DM and MDD respectively. In essence 224 participants took part in this study.

The prevalence of diabetes mellitus rather than that of depression were used in sample size determination in this study because patients with diabetes mellitus were the index participants while patients with depression were the comparator participants.

\section{Participants}

Using a simple random sampling, 112 participants with DM were selected, ten every week from about 70 - 100 out-patients with DM that attend the diabetic clinic every Wednesday. They were interviewed while waiting to be seen by the consultant diabetologists at the clinic. MDD participants were consecutively recruited till the sample size required for the study was reached, matching with DM participants for gender. Inclusion criteria were patient's age range between 18 and 64 years with established diagnosis of type 1 or type 2 DM by a consultant diabe- tologist in UNTH, Enugu, and diagnosis made at least one year prior to the study, and patients with established diagnosis of MDD by DSM-IV criteria, as confirmed by a consultant psychiatrist, diagnosis also made at least one year prior to the study. Exclusion criteria were patients with significant cognitive impairment that was severe enough to affect ability to participate in the research interview and give informed consent, and unconscious patients and those too ill to participate in the study. Participants with established co-morbid diagnosis of DM and MDD, and receiving treatment for both conditions were excluded.

\section{Study instruments}

The instruments used for this study were the Sociodemographic Questionnaire for the socio-demographic variables such as the respondents' age, gender, marital status, employment status, and occupational status, determined with the International Standard Classification of Occupations (ISCO-88). ${ }^{35}$

The Religious Orientation Scale-Revised (ROS-R), also called the Intrinsic/Extrinsic (I/E) scale (revised), is a 14item scale that measures intrinsic and extrinsic religiosities. Eight items with three reversed scores (scale items 3, 10 and 14) measure the intrinsic orientation whereas six items, three items each measure the personal and social categories of extrinsicness. The original Religious Orientation Scale (ROS) was developed by Allport and Ross in 1967 but revised by Gorsuch and McPherson in 1989, and known as Religious Orientation Scale-Revised (ROSR) (or I/E revised). ${ }^{36}$ Reliability estimates for Intrinsic (I)-revised was 0.83, Extrinsic personal (Ep)-revised 0.57 , Extrinsic social (Es)-revised 0.58 and Extrinsic (E) -revised $0.65{ }^{36}$ This revised version was used in this study.

The Brief Religious Coping (Brief RCOPE) scale is a 14-item measure of religious coping with life stressors. The items are scored on a 4-point Likert ranging from $' 0=$ not at all' to ' $3=$ a great deal.' It has two subscales; the Brief RCOPE Positive and Brief RCOPE Negative, each with seven items. It was developed out of Pargament's programme of theory and research on religious coping, and is the most commonly used measure of religious coping in the literature. ${ }^{37}$ Brief RCOPE Positive and Brief RCOPE Negative subscales have high degrees of internal consistency (Cronbach $\alpha$ level of .90 and .81 respectively). ${ }^{37}$ 


\section{Procedure}

Patients with established diagnosis of diabetes mellitus who were present at the diabetic clinic on appointment were randomly selected and interviewed while waiting to be seen by the consultant diabetologists. Ten participants with DM that met the inclusion criteria and gave voluntary consent were interviewed. The sociodemographic questionnaire was the first to be administered to the participants followed by the ROS-R and the Brief RCOPE, privately. In each case, the interviewers read out the questions and recorded the participants' responses. Therefore, although all the questionnaires were self-report questionnaires, they were interviewer-administered to minimize bias. It took about 15 minutes to interview one participant. The participants with MDD were recruited from the out-patient clinics of FNH, Enugu which hold four times a week, and from the psychiatric out-patient clinics at UNTH, Enugu which hold twice a week. MDD participants were consecutively recruited with same instruments in same order, matching for gender.

Recruitment of participants was over a 12-week period; adequate care taken not to interview a single participant twice over this period by tagging the case note. Two hundred and forty participants were recruited, but 16 were dropped because they could not complete the interview. Eight participants with diabetes (six males, two females) were in a hurry to leave the hospital premises after seeing their internal physicians while eight (six males and two females) participants with depression who became disinterested midway into the interview and could not complete the interview were excluded in the data analysis.

\section{Statistical analysis}

Statistical analysis was carried out using the Statistical Package for the Social Sciences for windows (SPSS-PC) version 16. Basic descriptive statistics was used to present the socio-demographic profile. The socio-demographic variables of both groups of study participants with DM or MDD were compared using the independent t-test.
In this study; the ages of participants were dichotomized into two.The mean age of the index participants (DM) $($ Mean+SD $=51.7+9.4)$, approximately 52 would have been used as cut-off but was regarded as being too high since participants with type $1 \mathrm{DM}$ (juvenile onset) were also involved in the study. Instead, the statistical range $(=42)$, the difference between the highest and lowest age of the index participants was used as cut-off. This range $(=42)$, approximates middle age of 40 and above when adult onset DM is typically said to begin. Therefore, participants with age $\leq 42$ were designated as 'younger' and those $\geq 43$ designated as 'older'. The 'older' group represents the 'middle aged/elderly' participants. The occupational status of participants were dichotomized into two; 'high' occupational status and 'low' occupational status. Participants with occupation belonging to the Major Group 2 (Professionals) and Major Group 3 (Technicians $\&$ Associate professionals) of the International Standard Classification of Occupations (ISCO-88) were designated in this study to be 'high' and others from Clerks (Major Group 4) to students (Major Group 11) were designated as 'low'. These dichotomizations were done to convert these variables to categorical variables so that appropriate test statistics could be applied.

\section{Results}

All participants in this study were Christians, and were of the Igbo ethnic group. Females were in the majority constituting about $63 \%$ of the participants. The age range was $22-64$ years $($ Mean $+\mathrm{SD}=51.7+9.4)$ for the participants with DM, and $20-64($ Mean + SD $=38.1+11.9)$ for participants with MDD showing a significant difference in their baseline mean ages $(t=9.5, p<0.001)$ for the two groups of participants with DM and MDD.

Table 1 showed that there were no significant differences in intrinsic religiosity $(t=1.47, p=0.15)$, extrinsic religiosity $(t=0.76, p=0.45)$ and religious coping styles, the Brief RCOPE positive ( $t=0.80, \mathrm{p}=0.43$ ) between younger DM and younger MDD participants. In other words, Younger people with MDD and DM used religious resources and religious coping methods to the same extent. 
Table 1: Association in religiosity and religious coping between the 'young' in both groups

\begin{tabular}{|c|c|c|c|c|c|}
\hline $\begin{array}{l}\text { Religiosity \& Religious } \\
\text { Coping }\end{array}$ & Age Group & Mean & $\pm \mathrm{S} / \mathrm{D}(\mathrm{R} \& \mathrm{RC})^{*}$ & $\mathrm{t}$ & $\mathrm{p}$ value \\
\hline \multirow[t]{2}{*}{ ROS total } & Younger DM & 52.14 & 5.17 & 1.53 & 0.13 \\
\hline & Younger MDD & 54.86 & 6.26 & & \\
\hline \multirow[t]{2}{*}{ ROS intrinsic } & Younger DM & 33.50 & 4.24 & 1.47 & 0.15 \\
\hline & Younger MDD & 35.51 & 4.78 & & \\
\hline \multirow[t]{2}{*}{ ROS extrinsic } & Younger DM & 18.64 & 3.95 & 0.76 & 0.45 \\
\hline & Younger MDD & 19.35 & 3.08 & & \\
\hline \multirow[t]{2}{*}{ ROS Extrinsic personal } & Younger DM & 13.43 & 3.06 & 1.07 & 0.29 \\
\hline & Younger MDD & 14.04 & 1.71 & & \\
\hline \multirow[t]{2}{*}{ ROS Extrinsic social } & Younger DM & 5.21 & 2.75 & 0.13 & 0.90 \\
\hline & Younger MDD & 5.31 & 2.62 & & \\
\hline \multirow[t]{2}{*}{ Brief RCOPE positive } & Younger DM & 20.29 & 1.73 & 0.80 & 0.43 \\
\hline & Younger MDD & 20.57 & 1.13 & & \\
\hline \multirow[t]{2}{*}{ Brief RCOPE negative } & Younger DM & 3.29 & 1.82 & 1.48 & 0.14 \\
\hline & Younger MDD & 4.75 & 3.62 & & \\
\hline
\end{tabular}

*R $=$ Religiosity. $\quad \mathrm{RC}=$ Religious Coping

In table 2, the older (middle aged/elderly) participants with MDD were more religious with greater intrinsic religiosity $(t=5.02, p<0.001)$, and used positive religious coping method, the Brief RCOPE positive $(\mathrm{t}=2.31, \mathrm{p}=$ 0.02 ) more than the older (middle aged/elderly) participants with DM.

\begin{tabular}{|c|c|c|c|c|c|}
\hline $\begin{array}{l}\text { Religiosity\& Religious } \\
\text { Coping }\end{array}$ & Age Group & Mean & $+\underset{*}{+} / \mathrm{D}(\mathrm{R} \& \mathrm{RC})$ & $\mathrm{t}$ & $\mathrm{p}$ value \\
\hline \multirow[t]{2}{*}{ ROS total } & Older DM & 51.83 & 6.66 & 4.41 & 0.00 \\
\hline & Older MDD & 57.23 & 4.75 & & \\
\hline \multirow[t]{2}{*}{ ROS intrinsic } & Older DM & 33.12 & 5.36 & 5.02 & 0.00 \\
\hline & Older MDD & 37.89 & 2.74 & & \\
\hline \multirow[t]{2}{*}{ ROS extrinsic } & Older DM & 18.70 & 3.21 & 1.01 & 0.31 \\
\hline & Older MDD & 19.34 & 3.21 & & \\
\hline \multirow{2}{*}{$\begin{array}{l}\text { ROS } \\
\text { personal }\end{array}$} & Older DM & 13.98 & 1.92 & 1.37 & 0.17 \\
\hline & Older MDD & 14.46 & 1.24 & & \\
\hline \multirow[t]{2}{*}{ ROS Extrinsic social } & Older DM & 4.72 & 2.38 & 0.33 & 0.74 \\
\hline & Older MDD & 4.89 & 2.69 & & \\
\hline \multirow[t]{2}{*}{ Brief RCOPE positive } & Older DM & 20.45 & 1.33 & 2.31 & 0.02 \\
\hline & Older MDD & 20.97 & 0.17 & & \\
\hline \multirow[t]{2}{*}{ Brief RCOPE negative } & Older DM & 3.10 & 2.94 & 0.12 & 0.90 \\
\hline & Older MDD & 3.17 & 2.67 & & \\
\hline
\end{tabular}

$* \mathrm{R}=$ Religiosity. $\quad \mathrm{RC}=$ Religious Coping 
As shown on table 3 , females with MDD were more religious with higher intrinsic religiosity $(\mathrm{t}=3.85, \mathrm{p}<0.001)$, and used positive religious coping (Brief RCOPE posi- tive) method ( $\mathrm{t}=2.34, \mathrm{p}=0.02)$ more than the males with MDD, though the males with MDD were more involved in extrinsic religious social activities $(\mathrm{t}=2.07, \mathrm{p}=0.04)$ than the females with MDD.

Table 3: Association between religiosity, religious coping and gender in depression (MDD).

\begin{tabular}{llllll}
$\begin{array}{l}\text { Religiosity \& Religious } \\
\text { Coping }\end{array}$ & Gender & Mean & $\pm \mathrm{S} . \mathrm{D}(\mathrm{R} \& \mathrm{RC})^{*}$ & $\mathrm{t}$ & $\mathrm{p}$ value \\
\hline ROS total & Male & 53.81 & 7.30 & 2.54 & 0.01 \\
& Female & 56.67 & 4.63 & & \\
ROS intrinsic & Male & 34.31 & 5.48 & 3.85 & 0.00 \\
& Female & 37.41 & 3.06 & & \\
ROS extrinsic & Male & 19.50 & 3.62 & 0.40 & 0.69 \\
& Female & 19.26 & 2.77 & & \\
ROS Extrinsic personal & Male & 13.67 & 1.84 & 2.67 & 0.01 \\
& Female & 14.47 & 1.34 & & \\
ROS Extrinsic social & Male & 5.83 & 3.06 & 2.07 & 0.04 \\
\multirow{2}{*}{ Brief RCOPE positive } & Female & 4.79 & 2.28 & & \\
\multirow{2}{*}{ Brief RCOPE negative } & Male & 20.43 & 1.27 & 2.34 & 0.02 \\
& Female & 20.86 & 0.67 & & \\
& Male & 4.52 & 4.07 & 0.63 & 0.52 \\
*R = Religiosity. & Female & 4.10 & 2.97 & &
\end{tabular}

Males with DM as shown on table 4, had higher scores in $=2.92, \mathrm{p}<0.001$ ) more than females with DM though extrinsic religiosity $(t=2.09, \mathrm{p}=0.04)$ and used the nega- there was no significant difference in their intrinsic religitive religious coping (Brief RCOPE negative) method $(t \quad$ osity scores $(t=0.89, p=0.37$ ).

Table 4: Association between religiosity, religious coping and gender in diabetes mellitus.

\begin{tabular}{llllll}
$\begin{array}{l}\text { Religiosity\& } \\
\text { Religious Coping }\end{array}$ & & Mean & ${ }^{+S . D}(\mathrm{R} \& \mathrm{RC})^{*}$ & $\mathrm{t}$ & $\mathrm{p}$ value \\
\hline ROS total & Male & 53.26 & 5.73 & 1.79 & 0.08 \\
& Female & 51.03 & 6.78 & & \\
ROS intrinsic & Male & 33.74 & 4.92 & 0.89 & 0.37 \\
& Female & 32.83 & 5.39 & & \\
ROS extrinsic & Male & 19.52 & 3.10 & 2.09 & 0.04 \\
& Female & 18.20 & 3.32 & & \\
ROS extrinsic & Male & 14.40 & 1.21 & 1.97 & 0.05 \\
personal & Female & 13.61 & 2.42 & & \\
ROS extrinsic social & Male & 1.71 & 0.46 & 0.77 & 0.44 \\
Brief RCOPE & Female & 1.64 & 0.48 & & \\
positive & Male & 20.60 & 1.04 & 0.99 & 0.32 \\
Brief RCOPE & Female & 20.33 & 1.55 & & \\
negative & Male & 4.10 & 3.30 & 2.92 & 0.00 \\
& Female & 2.54 & 2.31 & & \\
*R = Religiosity. & & RC $=$ Religious Coping & &
\end{tabular}


As displayed on table 6, participants with DM in the 'low' occupational status used the positive religious coping (Brief RCOPE positive) style $(\mathrm{t}=2.96, \mathrm{p}<0.001)$ more than those with DM in the 'high' occupational group just as there was no difference in the use of religious resourc- es and religious coping style of participants with MDD in the 'high' and 'low' occupational groups as shown on table 5. Other details of the results as they relate to the sociodemographic variables, religiosity and coping are as presented in the tables below.

Table 5 shows the association between religiosity, religious coping and occupational status in participants with depression (MDD).

\begin{tabular}{|c|c|c|c|c|c|}
\hline $\begin{array}{l}\text { Religiosity \& Religious } \\
\text { Coping }\end{array}$ & Occupational status & Mean & $\pm \mathrm{S} . \mathrm{D}(\mathrm{R} \& \mathrm{RC})^{*}$ & $\mathrm{t}$ & $\mathrm{p}$ value \\
\hline \multirow[t]{2}{*}{ ROS total } & High & 54.38 & 3.86 & 0.89 & 0.37 \\
\hline & Low & 55.80 & 6.18 & & \\
\hline \multirow[t]{2}{*}{ ROS intrinsic } & High & 35.81 & 3.51 & 0.43 & 0.67 \\
\hline & Low & 36.32 & 4.52 & & \\
\hline \multirow[t]{2}{*}{ ROS extrinsic } & High & 18.56 & 2.34 & 1.10 & 0.28 \\
\hline & Low & 19.48 & 3.21 & & \\
\hline \multirow[t]{2}{*}{ ROS Extrinsic personal } & High & 14.31 & 1.08 & 0.39 & 0.70 \\
\hline & Low & 14.15 & 1.66 & & \\
\hline \multirow[t]{2}{*}{ ROS Extrinsic social } & High & 4.25 & 1.69 & 1.53 & 0.13 \\
\hline & Low & 5.33 & 2.74 & & \\
\hline \multirow[t]{2}{*}{ Brief RCOPE positive } & High & 20.81 & 0.54 & 0.52 & 0.60 \\
\hline & Low & 20.68 & 1.01 & & \\
\hline \multirow[t]{2}{*}{ Brief RCOPE negative } & High & 4.35 & 4.0 & 0.32 & 0.74 \\
\hline & Low & 4.3 & 3.2 & & \\
\hline
\end{tabular}

$* \mathrm{R}=$ Religiosity. $\quad \mathrm{RC}=$ Religious Coping

Table 6: Association between religiosity, religious coping and occupation in diabetes mellitus (DM).

\begin{tabular}{|c|c|c|c|c|c|}
\hline $\begin{array}{l}\text { Religiosity \& } \\
\text { Religious } \\
\text { Coping }\end{array}$ & Occupational status & Mean & $\pm \mathrm{S} . \mathrm{D}(\mathrm{R} \& \mathrm{RC})^{*}$ & $\mathrm{t}$ & $\mathrm{p}$ value \\
\hline \multirow[t]{2}{*}{ ROS total } & High & 49.91 & 5.19 & 1.64 & 0.11 \\
\hline & Low & 52.37 & 6.70 & & \\
\hline \multirow[t]{2}{*}{ ROS intrinsic } & High & 31.78 & 4.56 & 1.44 & 0.15 \\
\hline & Low & 33.53 & 5.34 & & \\
\hline \multirow[t]{2}{*}{ ROS extrinsic } & High & 18.13 & 4.28 & 0.93 & 0.36 \\
\hline & Low & 18.84 & 2.99 & & \\
\hline \multirow{2}{*}{$\begin{array}{l}\text { ROS Extrinsic } \\
\text { personal }\end{array}$} & High & 13.39 & 2.73 & 1.35 & 0.18 \\
\hline & Low & 14.04 & 1.88 & & \\
\hline \multirow{2}{*}{$\begin{array}{l}\text { ROS } \\
\text { social }\end{array}$} & High & 1.52 & 0.51 & 1.70 & 0.09 \\
\hline & Low & 1.71 & 0.46 & & \\
\hline \multirow{2}{*}{$\begin{array}{l}\text { Brief RCOPE } \\
\text { positive }\end{array}$} & High & 19.70 & 1.99 & 2.96 & 0.00 \\
\hline & Low & 20.62 & 1.11 & & \\
\hline \multirow{2}{*}{$\begin{array}{l}\text { Brief } \\
\text { negative }\end{array}$} & High & 2.26 & 3.08 & 1.66 & 0.10 \\
\hline & Low & 3.35 & 2.72 & & \\
\hline
\end{tabular}




\section{Discussion}

The study is about the association of socio-demographic characteristics with religiosity and religious coping among two clinical groups of participants with separate diagnosis of depression or diabetes mellitus. The age distribution of religiosity is similar to what has been obtained in the United States, although the US studies were in the general population. ${ }^{23,24}$ This study found the older participants with depression or diabetes mellitus appeared to be more religious than the younger participants. Among the older participants, those with depression appeared to be more religious than the group with diabetes mellitus with greater intrinsic religiosity scores. This seems to suggest that religiosity and religious coping could be more among people with depression than among those with diabetes mellitus. The explanation for this finding is not clear. However, since mental illness is poorly conceptualized among Africans ${ }^{38}$ and in most cases these mental disorders are attributed to spiritual causation ${ }^{39}$, those with mental disorders (MDD) in this study therefore would more likely resort to religious/spiritual coping resources than those with physical disorders (DM) believed to have less spiritual/religious undertone.

Religiosity and religious coping appear to be more common among females than in their males' counterparts in this study; females having greater intrinsic religiosity scores than the males. This again has been found in previous studies. ${ }^{23,24}$ The mentally ill female patients (with depression) appear to be more religious than their physically ill (with diabetes) counterparts. The males with DM had higher extrinsic religiosity scores than females with DM probably because males are said to be more involved in socialization activities generally than the females. Results from the Brazilian national survey ${ }^{26}$ of religious involvement and sociodemographic factors also found that older age and female gender were independently associated with higher levels of subjective and organizational religiousness. This is line with our findings and studies from other countries including the United States thus indicating similarities across cultures.

Socio-economic status (SES) is usually measured by the level of income earned by the individual, but that may be determined by the individual's level of education, his occupational and employment status. The most important determinant of SES is the individual's occupational status. This is because though an individual in occupational status ISCO 9 (Elementary Occupation) may be gainfully employed, he may not earn enough income under normal circumstances as those in ISCO 2 (Professionals) who are also gainfully employed, and so are in same employment status but different occupational status. The same principles apply in this study. Occupational status was taken as the most important determinant of SES. Participants with diabetes who were in the low occupational status appeared to have adopted positive religious coping strategies to cope with their condition in this study. Studies have suggested that religious coping is a measure of functional religiousness. ${ }^{25}$ It thus suggests that people in the low occupational status were more functionally religious than their counterparts in the high occupational status. This finding appears to be in keeping with what has been found previously elsewhere that religiosity and religious coping negatively correlated with socio-economic status (SES).$^{30-32}$ However, in the Brazilian study, ${ }^{26}$ educational level and income which are measures of SES were not independently associated with religious involvement variables.

\section{Conclusion}

Participants in this study varied in their use of religion as a means of coping with the stress of living with diabetes mellitus or depression according to their socio-demographic profile. Also, people with depression (mentally ill) appeared to be more religious, and were more likely to resort to religious coping compared with people with diabetes mellitus (physical illness). Efforts should be made to elicit religiosity among mentally ill patients during Psychiatric assessment, and to employ this valuable resource in the optimal management of patients in Psychiatry.

\section{Study limitations}

The study samples were entirely Igbos and christians, therefore the applicability of our findings to non-christian populations is uncertain. It is a cross sectional study, therefore causal relationships cannot be inferred. Because the age of onset of diabetes type 2 is higher than the onset of depression, and because the patients treated for depression at the psychiatric clinics were generally of younger age, one-on-one comparative matching for age could not be achieved. This is a limitation. 


\section{Acknowledgements.}

The authors would like to thank the management and members of staff of Federal Neuropsychiatric Hospital, Enugu and the University of Nigeria Teaching Hospital, Enugu for their assistance.

\section{References}

1. WHO. Depression: Fact sheet. World Health Organization media centre, 2012. Available at: http://www.who. int/mediacentre/factsheets/fs369/en/. [Accessed 25 February, 2015].

2. WHO. Diabetes: Fact sheet. World Health Organization media centre, 2015. Available at: http://www.who. int/mediacentre/factsheets/fs312/en/. [Accessed 25 February, 2015].

3. Gavard JA, Lustman PJ, Clouse RE. Prevalence of depression in adults with diabetes. An epidemiological evaluation. Diabetes Care, 1993; 16:1167-1178

4. Hopwood P and Stephens RJ. Depression in lung cancer: prevalence and risk factor from quality-of-life data. $J$ Clin Oncol, 2000; 18(4):893-903.

5. Rubin RR, Payrot M. Psychological Issues and Treatments for People with Diabetes. J Clin Psychol. 2001; 57:457. Doi: 10.1002/jclp.1041. (422).

6. Tuncay T, Muşabak I, Engin Gok D, Kutlu M. The relationship between anxiety, coping strategies and characteristics of patients with diabetes. Health Qual Life Outcomes, 2008; 6:79-87.

7. Maiyaki MB, Garbati MA. The burden of non-communicable diseases in Nigeria; in the context of globalization. Ann Afr Med, 2014; 13(1):1-10. DOI: 10.4103/15963519.126933.

8. International Diabetes Federation. IDF Diabetes, 6 ed. Brussels, Belgium: International Diabetes Federation, 2013. http://www.diabetesatlas.org

9. Guariguata L, Whiting DR, Hambleton I, Beagley J, Linnenkamp U, Shaw JE. Global estimates of diabetes prevalence for 2013 and projections for 2035. Diabetes Res Clin Pr, 2014; 103(2): 137-149.

10. Pan A, Lucas M, Sun Q, van Dam RM, Franco OH, Manson JE, Willet WC, Ascherio A and Hu FB. Bidirectional association between depression and type 2 diabetes mellitus in women. Arch Intern Med. 2010; 170(21):18841891.

11. Renn BN, Feliciano L, Segal DL. The bidirectional relationship of depression and diabetes: A systematic review. Clin Psychol Rev, 2011; 31(8): 1239 -1246.
12. Koenig HG, McCullough ME, Larson DB. Handbook of Religion and Health. New York: Oxford University Press, 2001.

13. Braam AW, Beekman ATF, Deeg DJH, Smith JH, Van Tilburg W. Religiosity as a protective or prognostic factor of depression in later life; results from the community survey in the Netherlands. Acta Psychiatr Scand, 1997; 96:199-205.

14. Koenig HG, George LK, Peterson BL. Religiosity and remission of depression in medically ill older patients. Am J Psych, 1998; 155(4):536-542.

15. Gartner J, Larson DB, Allen G, Religious commitment and mental health: a review of the empirical literature. $J$ Psychol Theol, 1991; 19(1):6-25.

16. Koenig, H. G. Religion and medicine II: Religion, mental health, and related behaviours. Int J Psychiat Med, 2001b; 31(1), 97-109.

17. Pargament KI and Lomax JW. Understanding and addressing religion among people with mental illness. World Psychiatry, 2013; 12 (1): 26-32.

18. Koenig HG. Research on religion, spirituality and mental health: A Review. Can J Psychiatry, 2009; 54(5):28391.

19. Tarakeshwar N, Vanderwerker LC, Paulk E, Pearce MJ, Kasl SV, Prigerson HG. Religious coping is associated with quality of life of patients with advanced cancer. $J$ Palliat Med, 2006; 9(3):646-657.

20. Koenig, H. G. Religion and medicine III: Developing a theoretical model. Int J Psychiat Med, 2001c; 31(2), 199-216.

21. Agara AJ, Makanjuola AB, Morakinyo O. Management of perceived mental health problems by spiritual healers: a Nigerian study. Afr J Psychiatry, 2008; 11:113118.

22. Aina OF. 'Psychotherapy by environmental manipulations' and the observed symbolic rites on Prayer Mountains in Nigeria. Ment Health Relig Cult, 2006; 9(1):1-13.

23. Ferraro KF and Koch JR. Religion and health among black and white adults: Examining social support and consolation. J Sci Stud Relig, 1994; 33(4): 362-375.

24. Koenig HG. Religion, Spirituality and Medicine: Research findings and implications for clinical practice. South Med J, 2004; 97(12):1194-1200.

25. Phelps AC, Maciejewski PK, Nilsson M, Balboni TA, Wright AA, Paulk ME, Trice E, Schrag D, Peteet JR, Block SD, Prigerson HG. Religious coping and use of intensive life-prolonging care near death in patients 
with advanced cancer. $J A M A, 2009 ; 301(11): 1140-1147$. doi:10.1001/jama.2009.341.

26. Moreira-Almeida A, Pinsky I, Zaleski M, Laranjeira

R. Religious involvement and sociodemographic factors: a Brazilian national survey. Rev Psiq Clín. 2010; 37(1):12-5. 27. Fitchett G, Murphy PE, Kim J, Gibbons JL, Cameron JR and Davis JA. Religious struggle: prevalence and mental health risks in diabetic, congestive heart failure, and oncology patients. Int J Psychiat Med, 2004; 34 (2): 179-196. 28. Wallace JM Jr, Forman TA, Caldwell CH, Willis DS. Religion and U.S. secondary school students: current patterns, recent trends, and sociodemographic correlates. Youth \& Society, 2003; 35 (1): 98-125 Doi: 10.1177/0044118x03254564.

29. Saleh M. On the Road to Heaven: Self-Selection, Religion, and Socioeconomic Status, 2013. https://www. aeaweb.org/aea/2013conference/program/retrieve.php. (Accessed 10 January 2015).

30. Heaton TB. Religion and socioeconomic status in developing nations: A comparative approach. Soc.Compass, 2013; 60 (1): 97-114. Doi:10.1177/0037768612471772

31. Schieman S. Socioeconomic status and beliefs about God's influence in everyday life. Sociol Relig, 2010; 71 (1): 25-51. Doi: 10.1093/socrel/srq004.

32. Jones RP, Cox D, Navarro-Rivera J, Dionne EJ. Jr. and Galston WA. The 2012 American Values Survey; How
Catholics and the Religiously Unaffiliated Will Shape the 2012 Election and Beyond, 2013. http://www.publicreligion.org/. (Accessed 10 January 2015).

33. Araoye MO. Sample Size determination. In: Research methodology with statistics for health and social sciences. Ilorin (Nigeria). Nathadex Publishers, 2003:115-121.

34. Erasmus RT, Fakeye T, Olukoga O, Okesina AB, Ebomoyi E, Adeleye $\mathrm{M}$ and Arije A. Diabetes Mellitus in a Nigerian Population. Trans R Soc Trop Med Hyg, 1989; 83(3): 417-418.

35. ILO. International standard classification of occupations (ISCO-88). Geneva: International Labour Organisation (ILO) ed., 1990.

36. Gorsuch R, Mcpherson S. Intrinsic/extrinsic measurement: I/E-revised and single-item scales. J Sci Stud Relig 1989; 28(3): 348-354.

37. Pargament K, Feuille M, Burdzy D. The Brief RCOPE: current psychometric status of a short measure of religious coping. Religions, 2011; 2:51-56. Doi 10.3390/ rel2010051.

38. Audu IA, Idris SH, Olisah VO, Sheikh TL. Stigmatization of people with mental illness among inhabitants of a rural community in northern Nigeria. Int J Soc Psychiatry, 2013; 13(59); 1 55-60.

39. Uwakwe R. The views of some selected Nigerians about mental disorders. The Niger Postgrad Med J, 2007; 14 (4):319-324. 